\title{
Evolutionary Game Analysis of China's Housing Industrialization Incentive Policy
}

\author{
Yan Liu \\ School of Economics and Management \\ Beijing Jiaotong University \\ Beijing, China
}

\author{
Yu Luo \\ School of Economics and Management \\ Beijing Jiaotong University \\ Beijing, China
}

\begin{abstract}
In order to implement the concept of sustainable development of real estate, China's residential industrialization has integrated energy conservation, environmental protection and high efficiency on the basis of maintaining the same level of quality as before. China's government departments have given relevant incentive policies for the development trend of residential industrialization, which will inject strong momentum into the development of residential industrialization. Based on the interaction behavior of residential industrialization stakeholders, this paper uses the relevant theory of evolutionary game theory to construct an evolutionary game model of government and real estate developers, and analyzes the transmission mechanism of incentive policies for residential industrialization in China.
\end{abstract}

Keywords-housing

industrialization;

incentives; evolutionary game

\section{INTRODUCTION}

Housing Industry Modernization often abbreviated as "Housing Industrialization", initially means the modernization of the construction model, and modern meaning is the industrialization of all properties. The definition of industrialization in the initial stage was proposed by Japanese scholars in 1968. It is based on the use of related technologies and refers to the relevant standardization system of the residential department, which constitutes a community of interests in the research, installation and property of the entire housing cycle. The development period of foreign residential industrialization is much longer than domestic. After the Second World War, the relevant research results of residential industrialization have already appeared. In the context of the high degree of damage and loss in the Second World War, countries such as Europe, America, and Japan began to explore the industrialization of housing in order to ensure the supply demand of housing [1]. In the long-term development process, these countries have combined with the actual situation to formulate a series of promotion policies, which have made great progress in legislation, finance and finance, and the development of housing has basically met market demand. Barlow [2] proposed that only in the selection and application of large-scale customized production mode, housing can reach the requirements of consumers to the greatest extent, and has a high market competitiveness. Yoonseok [3] and others have developed an information system suitable for residential construction, which greatly improves the construction efficiency of the house and controls the overall construction cost. Jose P. Duarte [4] developed an auxiliary algorithm for housing construction that has had a major impact on mass-customized residential design. Studies have shown that the common form of residential construction in North America is the assembly of low-rise wood structures [5]. Matsumura [6] completed the efficient integration of resources on the basis of e-commerce, greatly improving construction efficiency and reducing project costs. Most of the analysis related to the industrialization of housing in foreign countries is concentrated on the contents of modularization and information systems. In China, we need to accelerate the development of residential industrialization on the basis of studying the experience of foreign developed countries and combining with the market demand of China. In order to achieve good residential construction in China, in the actual construction, high-quality construction materials must be selected, which directly leads to the cost of residential construction is generally higher than that of traditional houses [7]. In addition, China's corresponding promotion policy has not reached a higher level of promotion is also one of the reasons for the continued low level of China's residential industrialization development.

\section{THEORETICAL ANALYSIS}

\section{A. Incentive Theory}

The main content of the motivation theory includes information mechanism and incentive mechanism. The socalled incentive theory refers to the incentives provided to the participants to meet the requirements of the mechanism creators when they are chasing their own goals. In the field of economics, conventional incentive theory usually regards human beings as single members who only pursue more interests. It is assumed that the maximization of interests is the starting point for people to consider and act. At this time, the key to the creation of related mechanisms is to target the relevant individuals. The specific income situation completes the incentive, but ignores the initiative of the individual members, resulting in a decline in their enthusiasm for work. The driving theory proposed by Hull et al., the humanistic concept proposed by Mecleland and Alderfer, and the cognitive theory proposed by Bruner and other scholars have 
lacks systematic design. There is no clear direction on the whole. Each region develops its own, and only pursues short-term benefits, resulting in a large amount of construction waste, which leads to waste of resources and energy.

2) Lack of effective economic policy support: In the process of promoting the industrialization of housing, the government has not fundamentally solved the market failure of residential industrialization due to the lack of relevant economic policies such as tax reduction and loan interest rate concessions. The solution to the problem only stayed in the government's call, issued a number of relevant opinions and expert discussions, and did not implement specific issues such as funds. Such as, priority is given to supporting residential industrialization enterprises, and giving preferential policies and support to the housing industrialization component system, building system and technical support system.

3) Lack of standardization and componentization: In the industrial policy that has been introduced to promote the industrialization of housing, there is a lack of relevant policies on the development of building standardization and implementation of the ministry. Standardization and ministry are the premise and foundation for industrialization. The system of building standards without establishing a system is not up to standard.

4) Lack of relevant policies to encourage technology research and development: Technology development in industrialization is extremely important. In the early stage of technology research and development, high cost investment is required, and most developers lack the motivation to promote industrialization. The government has not issued a policy to encourage technology research and development, and there is no subsidy for research funding. It is difficult to mobilize the enthusiasm of producers.

\section{B. Problems in Policy Implementation}

1) Problems in policy implementation: In the industrial policies that have been introduced, there are few policies that require developers to enforce them, which lacks practical significance. In addition, many policy implementations are too narrow to achieve the goal of rapidly promoting industrialization and intensive management, which is contrary to the original intention of residential industrialization.

2) Insufficient motivation: In the policies that have been introduced, there is a lack of relevant economic policies that motivate companies. When developing a residential project, there is no mandatory policy restriction on industrialization on the one hand, and no economic incentive on the other. Although the current backward construction model does not affect the company's high profits, it needs a lot of financial support in the early stage, and it will not generate economic incentives for the company, which will reduce the company's development profit. Although residential
1) No complete residential industrialization system: China's housing industrialization policy has not yet formed a complete system. In terms of industrial policy system, China 
houses compared with building traditional houses. We can set the probability that government agencies choose economic incentives to $x$, set the probability that government agencies choose spiritual incentives to $1-x$, set the proportion of individuals in the real estate developer group to $y$, build industrialized housing as the proportion of individuals building traditional houses. The ratio is set to $1-y$. Building an asymmetric model between government and developers. (as shown in "Table I")

TABLE I. EVOLUTIONARY GAME BETWEEN GOVERNMENT AND REAL ESTATE DEVELOPERS

\begin{tabular}{|c|c|c|}
\hline \multirow{2}{*}{ Government } & \multicolumn{2}{|c|}{ Real estate developers } \\
\hline & $\begin{array}{c}\text { Housing industrialization } \\
y\end{array}$ & $\begin{array}{c}\text { Traditional } \\
1-y\end{array}$ \\
\hline $\begin{array}{c}\text { Economic } \\
\text { incentive } \\
\mathrm{x}\end{array}$ & $\begin{array}{c}\pi_{1}+\pi_{2}+\pi_{3}-c_{1}-c_{2} \\
\pi_{1}+\pi_{2}+c_{2}-c_{1}\end{array}$ & $\pi_{0}-c_{1}$ \\
\hline $\begin{array}{c}\text { Mental } \\
\text { stimulation } \\
1-\mathrm{x}\end{array}$ & $\pi_{1}+\pi_{4} \quad \pi_{1}^{\prime}+\pi_{2}^{\prime}-c_{1}^{\prime}$ & $\pi_{0} \quad \pi_{0}^{\prime}$ \\
\hline
\end{tabular}

\section{B. Evolutionary Stability Strategy Analysis}

For the government and the developers, in the limited rational repetitive game, refer to the several games that are often generated before, carry out the corresponding imitation, learning and change their own strategies, and then achieve the evolutionary stable equilibrium.

According to "Table I", it can be concluded that the government's choice of economic incentives is:

$$
E_{11}=y\left(\pi_{1}+\pi_{2}+\pi_{3}-c_{1}-c_{2}\right)+(1-y)\left(\pi_{0}-c_{1}\right)
$$

The government chooses spiritual incentive income as:

$$
E_{12}=y\left(\pi_{1}+\pi_{4}\right)+(1-y) \pi_{0}
$$

The average expected return of the government is:

$$
\left.E_{1}=x E_{11}+(1-x) E_{12}=x y\left(b_{2}\right)+\pi_{3}-\pi_{4}-\mathrm{c}_{2}\right)-x c_{1}+y\left(\pi_{1}+\pi_{4}\right.
$$

The government's replication dynamic equation is:

$$
F(x)=\frac{d x}{d t}=x\left(E_{11}-E_{1}\right)=x(1-x)\left[\left(\pi_{2}+\pi_{3}-\pi_{4}-c_{2}\right) y-c_{1}\right]
$$

The benefits that developers get from using the industrialization model are:

$$
E_{21}=x\left(\pi_{1}^{\prime}+\pi_{2}^{\prime}+c_{2}-c_{1}^{\prime}\right)+(1-x)\left(\pi_{1}^{\prime}+\pi_{2}^{\prime}-c_{1}^{\prime}\right)
$$

The benefits of using traditional construction methods are:

$$
E_{22}=x \pi_{0}^{\prime}+(1-x) \pi_{0}^{\prime}
$$

The expected return of the real estate developer community is:

$$
E_{2}=y E_{21}=(1-y) E_{22}=y\left(c_{2} x+\pi_{1}^{\prime}+\pi_{2}^{\prime}-\pi_{0}^{\prime}-c_{1}^{\prime}\right)+\pi_{0}
$$


- Increase the government's expenditure on various subsidies and preferential measures for real estate developers adopting residential industrialization methods; minimize the cost incurred in formulating and promoting relevant standards and policies.

\section{CONCLUSION}

In the evolutionary game analysis of China's housing industrialization incentive policy, the key factors affecting game equilibrium are mainly divided into four parts. These four parts include the costs incurred by the government to promote the development of residential industrialization, the resources obtained from it, the environmental and social benefits, the costs paid by the developers and the benefits they receive.

\section{REFERENCES}

[1] Jia Dechang. Industrialized Residential Buildings Gradually Approaching [J]. China Engineering Consulting, 2010.

[2] Barlow J C P G D. Choice and delivery in housebuilding: Lessons from Japan for UK housebuilders [J]. Building Research and Information, 2003.

[3] Shin Y A S C H. Application of information technology for mass customization in the housing construction industry in Korea $[\mathrm{J}]$. Automation in Construction, 2008.

[4] P D J. A discursive grammar for customizing mass housing: The case of Siza's houses at Malagueira, 2005 [J]. Elsevier, 2005.

[5] Momaya K S K I. competitiveness of the Canadian construction industry: A comparison with Japan and the United States [J]. Canadian Journal of Civil Engineering, 1998.

[6] Yang L H B Y M. The application of solar technologies in building energy efficiency: BISE design in solar-powered residential buildings [J]. Technology in Society, 2014.

[7] Wang Gang. Economic Analysis of Housing Industrialization [J]. Journal of Shenzhen University (Humanities and Social Sciences), 2003.

the system can achieve the Pareto optimal effect. The basic criticality of the various equilibrium states of this system is judged by the relevant saddle point $\left(\mathrm{x}^{*}, \mathrm{y}^{*}\right)$. If you want to achieve Pareto optimal equilibrium using the industrialization model in both government and development, you must move to the lower left of the interface, and further rely on special evolutionary effects to achieve an incremental change in the initial state of the point.

The parameters change as follows:

- Need to reduce the extra cost of industrialization

- There is a need to increase the expected benefits of the industrialization program and the long-term benefits of the brand and other areas achieved by this approach

- It is necessary to increase the expectation of the government to use the economic incentives, the longterm income of the resources obtained by the developers using the industrialization model, and the expectations of social-level benefits (credit enhancement, etc.); some developers still choose to reduce the use of spiritual incentives. Expected parameters of long-term benefits in areas such as resources obtained from industrialization programs 